\title{
Compensated Medium Voltage 6-Pulse CSR Using Shunt Active Power Filters: Three Different Configurations
}

\author{
MS Hamada and MI Masoud*b \\ a Electrical Engineering Department, Arab Academy for Science and Technology, Alexandria, Egypt \\ ${ }^{*}$ Electrical and Computer Engineering Department, College of Engineering, Sultan Qaboos University, PO Box 33 , \\ PC 123, Al-Khoud, Muscat, Sultanate of Oman
}

Received 27 March 2013; accepted 2 July 2013

\begin{abstract}
The 6-pulse controlled AC/DC converter produces harmonics. The input current total harmonic distortion and the input power factor, which is firing delay angle dependent, are major drawbacks, and a compensation technique is mandatory. This paper introduces a compensated 6-pulse current sourcecontrolled rectifier with a shunt active power filter $(A P F)$ in different configurations. The shunt $A P F$ with predictive current control is coupled to the 6-pulse systems in three different compensation configurations. The $A P F$ is connected either directly to the front-end transformer primary or secondary side or via a transformer to reduce the filter side voltage. The comparison between these configuration is introduced; each configuration has merits and demerits. The comparison cannot be genuine. Simulation results are presented for a medium voltage converter which is scaled to allow low-voltage experimental confirmation.
\end{abstract}

Keywords: Shunt active filter, 6-pulse converter, Medium voltage, Predictive current control, and Harmonics.

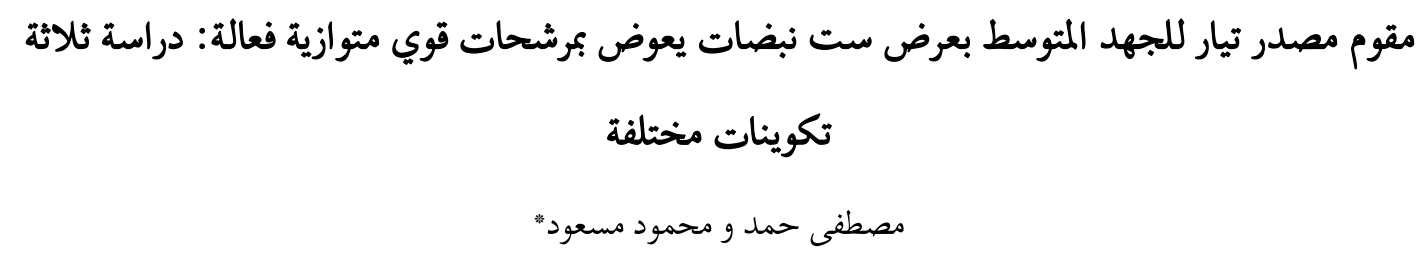




\section{Introduction}

The 6-pulse phase controlled AC/DC converter is often employed in low voltage $(L V)$ and medium voltage $(M V)$ systems for domestic and industrial applications (Wu 2006; Freitas et al. 2007; Rice 1994). Although controlled converters could be a good choice for higher power applications, due to their high efficiency and reliability (Wiechmann et al. 2008) they have major drawbacks in terms of $A C$ side power quality, input current total harmonic distortion (THD) and power factor ( $p f$ ) (Bose 2009). The $A C$ side harmonics occur at $6 \mathrm{p} \pm 1$ times the fundamental $(\mathrm{p}=1,2$, 3 ...etc.). The magnitude of these harmonics and the overall $T H D$ do not meet input current $T H D$ standard guidelines (Williams online). Moreover, the power factor depends on the current $T H D$ and the thyristor firing delay angle $(\alpha)$ (Rashid 2001).

$$
T H D=\frac{\sqrt{I_{s}^{2}-I_{s 1}^{2}}}{I_{S 1}}=31.1 \%
$$

Where, $I_{s}$ is the root mean square (RMS) supply current and $I_{s l}$ is the $R M S$ fundamental supply current. The power factor can be calculated as:

$$
p f=\frac{D P F}{\sqrt{1+T H D^{2}}}=0.955 \cos \alpha
$$

Where, $D P F$ is the displacement power factor, given by

$$
D P F=\cos \alpha
$$

Higher pulse configurations are possible (Choi and Cho 2000; Hamad et al. 2012), but the system cost and complexity are increased and the problem of power factor dependency on the firing delay angle remains (Wu 2006). A compensating technique is therefore mandatory to compensate for both the reactive and harmonic currents in order to improve the input current THD and $p f$ (Bose 2002). APF avoids passive filter drawbacks; moreover, it is durable and reliable (ElHabrouk et al. 2000; Akagi 1996; Akagi 2005; Rahmani et al. 2010; Singh and Solanki 2009).

In this paper, the 6-pulse converter is fed from a star/star front-end step-down transformer. Three $A P F$ connection configurations are considered, all with the objective of producing sinusoidal supply currents with a near unity power factor. In reference (Akagi et al. 1986), the $A P F$ is connected across the primary side. In the other configurations, the $A P F$ is connected via a high-bandwidth step-down transformer (Cheng et al. 1999). The $A P F$ is connected across the secondary side of the transformer (Tenca and Lipo 2004). For $M V$ applications, reducing the filter side voltage affects the system size, losses, and cost, and permits a higher switching frequency (Akagi 2005). The three compensation connections to be compared are:

- The $A P F$ connected to the primary side,

- The $A P F$ connected directly to the secondary side, and

- A secondary side connection via a high-bandwidth step-down transformer.

The $A P F$ is controlled to compensate the main current $T H D$ and $p f$. Simulations for a $M V$ system plus a scaled $L V$ practical system are used to enable performance comparison of the three configurations.

The voltage source inverter $(V S I-A P F)$ is used as it is more convenient for $A P F$ applications since it is lighter, cheaper, and expandable to a multilevel configuration to improve the performance at high power compensation with lower switching frequencies (Routimo et al. 2007). Also, in this paper, $A P F$ operation is based on the control strategy (Hamad et al. 2012; Massoud et al. 2004a) where harmonic and reactive current extractions are achieved using capacitor voltage control (Anuradha and Kothari 1998; Huang and $\mathrm{Wu}$ 1999), and the current control is achieved using predictive control. This control technique is simple, suitable for DSP implementation, and provides a constant switching frequency (Massoud et al. 2004b). The design details of $A P F$ are introduced in (Hamad et al. 2012).

After the introduction, the paper is organized as follows: Section 2 explains the compensation of a 6-pulse converter using a shunt $A P F$. Section 3 introduces configuration \#1. Section 4 introduces configuration \#2. Section 5 introduces configuration \#3. Finally, there is a discussion and conclusion.

\section{The 6-Pulse Converter Compensated for with a Shunt APF}

For $M V$ voltage applications, reducing the filter side voltage greatly affects system size and cost, and allows a higher switching frequency. The lower phase voltage requirement of a star connected primary is exploited, which is important in $M V$ applications. Typical parameters for the $M V$ transformer and the operating system parameters used in the simulations are listed in Appendix 1. A $2 \mathrm{kVA}, 415 \mathrm{~V}$, 6-pulse scaled prototype converter was used to investigate the performance of the different $A P F$ configurations. The operating conditions are common for all tested configurations; $v_{s}=$ $170 \mathrm{~V}, I_{d c}=1 \mathrm{~A}$ (switching devices are rated to $3 \mathrm{~A}$ ), 


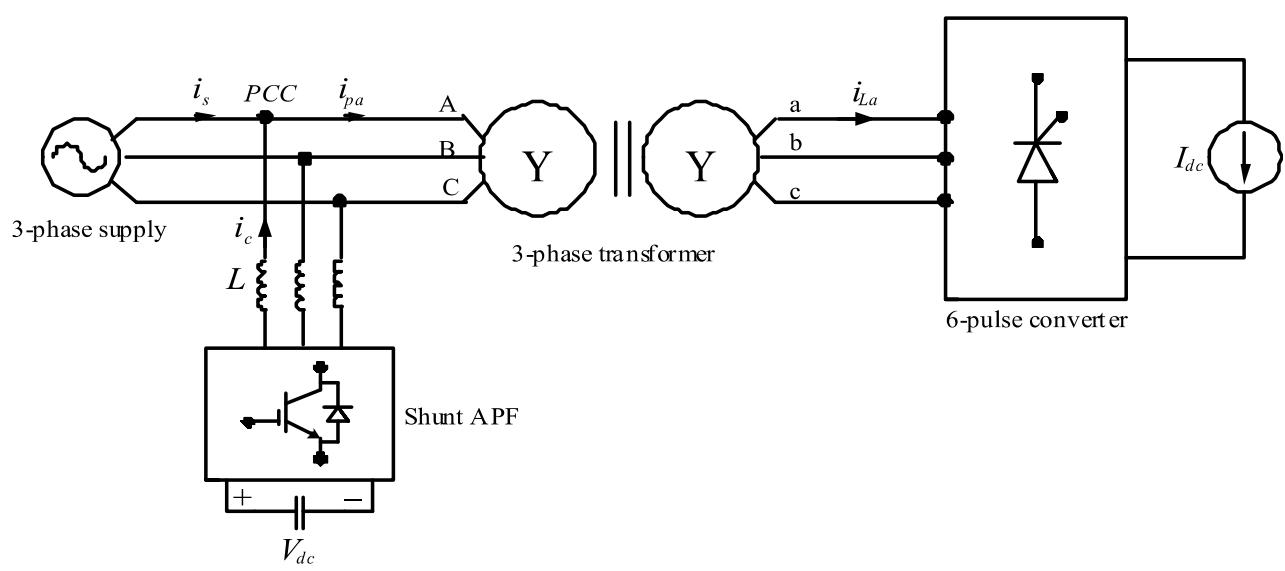

Figure 1. Configuration \# 1 APF connected to the primary side.

$f_{s w}=3.6 \mathrm{kHz}$ and $C=3.2 \mathrm{mF}$. The star/star windings of the prototype front-end transformer with parameters listed in Appendix 2 has a turns ratio of $N_{1} / N_{2}=2$. The operational environment is:

- A three-phase, three-wire system

- A balanced and sinusoidal voltage supply

- A negligible source impedance, and

- A balanced harmonic current-producing load.

All simulations and practical results are recorded for the representative phase ' $a$ ', as the system is a balanced three-phase one.

\section{Configuration \# 1}

In Fig. 1, the shunt $A P F$ is connected to the primary side of the front-end Y-Y transformer. The objective was to produce a sinusoidal supply current with near unity power factor. The $A P F$ inverter $D C$ side voltage $\left(V_{d c}\right)$ determines the voltage rating of the shunt $A P F$ switches, where $V_{d c}$ is greater than the line peak voltage at the point of common coupling (PCC). For a $M V$ system, the inverter requires semiconductor devices with high voltage ratings, possibly involving the series connection of switching devices.

\subsection{Simulation Results}

A MATLAB/Simulink (MathWorks, Inc., Natick, MA, USA) model of the $M V$ compensated 6-pulse converter was used to study the effect of the shunt $A P F$ on the system performance. The simulation models the supply as sinusoidal, balanced, or having negligible impedance. The capacitor voltage was controlled at $7.6 \mathrm{kV}$. Figure 2 shows the simulation results of parts $a-f$ when the 6-pulse converter operates at zero delay $(\alpha=0)$ and the $A P F$ is connected to shown PCC. The supply phase voltage $\left(v_{s}\right)$ is shown in part a. The primary current $\left(i_{p}\right)$ is shown in $b$, while $c$ shows the compensating current $\left(i_{c}\right)$ injected by the $A P F$. The supply current $\left(i_{s}\right)$ shown in d became sinusoidal after activation of the $A P F$ as the compensating current cancels the current harmonics in ip produced by the 6pulse converter. Parts $e$ and $f$ show the supply current frequency spectra before and after compensation. No triplen components arise in a balanced three-phase system.

\subsection{Practical Results}

The $L V$ prototype system representing configuration \#1 was tested experimentally, with a $12 \mathrm{mH}$, 3-phase interfacing inductor and the capacitor DC-voltage controlled at $400 \mathrm{~V}$. The test was performed with the converter operating in the rectifier mode $\left(\alpha=0-90^{\circ}\right)$. Parts a-c of Fig. 3 show the experimental results when the converter operates with $\alpha=45$. Part a shows that the harmonic and reactive current components of the front-end transformer ip were compensated for by the filter current $\left(i_{f}\right)$. The compensated is sinusoidal and in phase with the $v_{s}$. The spectra of the practical recorded supply current before and after activating the $A P F$ are shown in $b$ and $c$, respectively. The $T H D$ improved from $28.5 \%$ to $13.4 \%$, and the power factor improved from 0.6 to 0.912 .

\subsection{Discussion}

Configuration \#1 achieved the target of sinusoidal supply current with a near unity power factor, but may not be suitable for $M V$ applications because the $A P F$ was connected directly to the front-end $M V$ transformer primary. Consequently, the $M V$ inverter capacitor is large and costly. The filter bandwidth was limited as was the switching frequency due to the high voltage, possibly comprised of series connected semiconductor devices, which increases control complexity, filter size and cost. To overcome these voltage problems, the $A P F$ can be coupled to the $P C C$ via a highbandwidth, $M V$ transformer, but the costs would be 
(a)
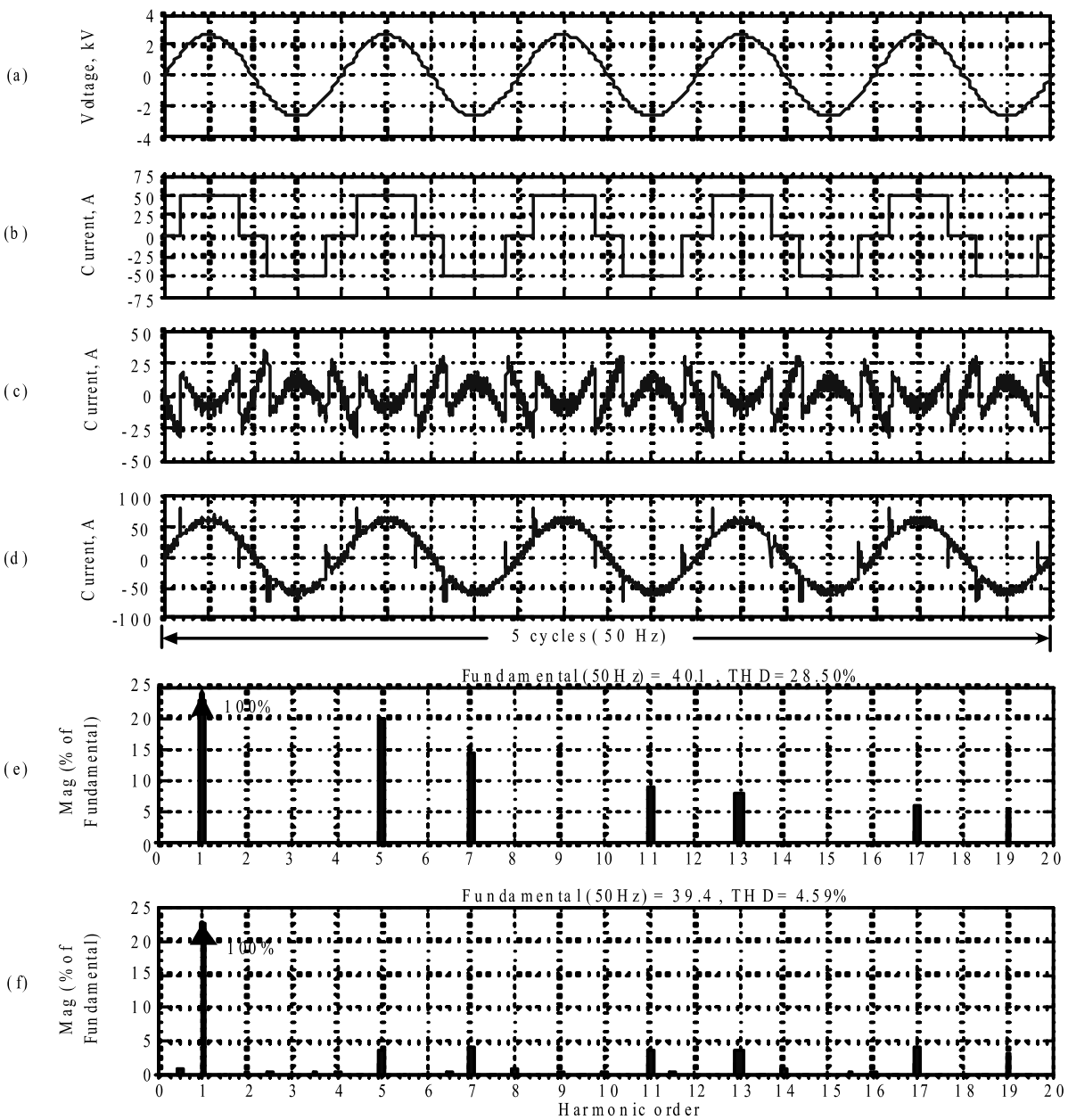

Figure 2. Configuration $\# 1$ at $\alpha=0^{\circ}$ : (a) supply phase voltage, $v_{s}$, (b) transformer primary current, $i_{p}$, (c) filter current, $i_{c}$, (d) compensated supply current, $i_{s}$, (e) spectrum of converter current, and (f) sp ectrum of compensated supply current.

high (Corasniti et al. 2008). The transformer ratings increase due to the transmission of the harmonics and reactive current. An alternative solution would be to connect the $A P F$ to the front-end transformer secondary side.

\section{Configuration \# 2}

APF is connected to the front-end transformer secondary as shown in Fig. 4. The same control concept is applied to all configurations, while it is detailed here for configuration \#2. The transformer secondary phase voltages and currents were measured and used in the control system. The turns ratio of the front-end transformer is $N_{1} / N_{2}=2$; thus, the voltage at the $P C C$ was half that of configuration \#1. This means that the capacitor voltage can be controlled at a lower voltage; consequently, semiconductor devices with a lower voltage rating can be used and, therefore, the operating switching frequency limit and the filter bandwidth can both be increased. The filter-side current was doubled.
A device voltage rating reduction only can be achieved if a step down transformer is used.

\subsection{Simulation Results}

The MATLAB model for the $M V$ 6-pulse converter was modified to study the compensation technique using configuration $\# 2$. The voltage reduction at the $P C C$ required a change to some of the operating parameters, as listed in Appendix 3. The simulation results for $\alpha=45$ are shown in Fig. 5. The secondary phase voltage was measured then scaled to synchronize the secondary reference current $\left(i^{*}{ }_{\text {sec }}\right)$. The supply phase voltage is shown in Fig. 5a. The converter current $\left(i_{L}\right)$ is shown in Fig. $5 \mathrm{~b}$ and the injected $A P F$ current is shown in Fig. 5c and compensates the harmonic and reactive currents.

The resulting sinusoidal transformer secondary current $\left(i_{\text {sec }}\right)$ is shown in Fig. $5 \mathrm{~d}$. By transformer action, $i_{\text {sec }}$ was transformed to the primary side. The primary current was the supply current $\left(i_{s}\right)$ as shown in $e$. The supply current was sinusoidal and in phase with the 

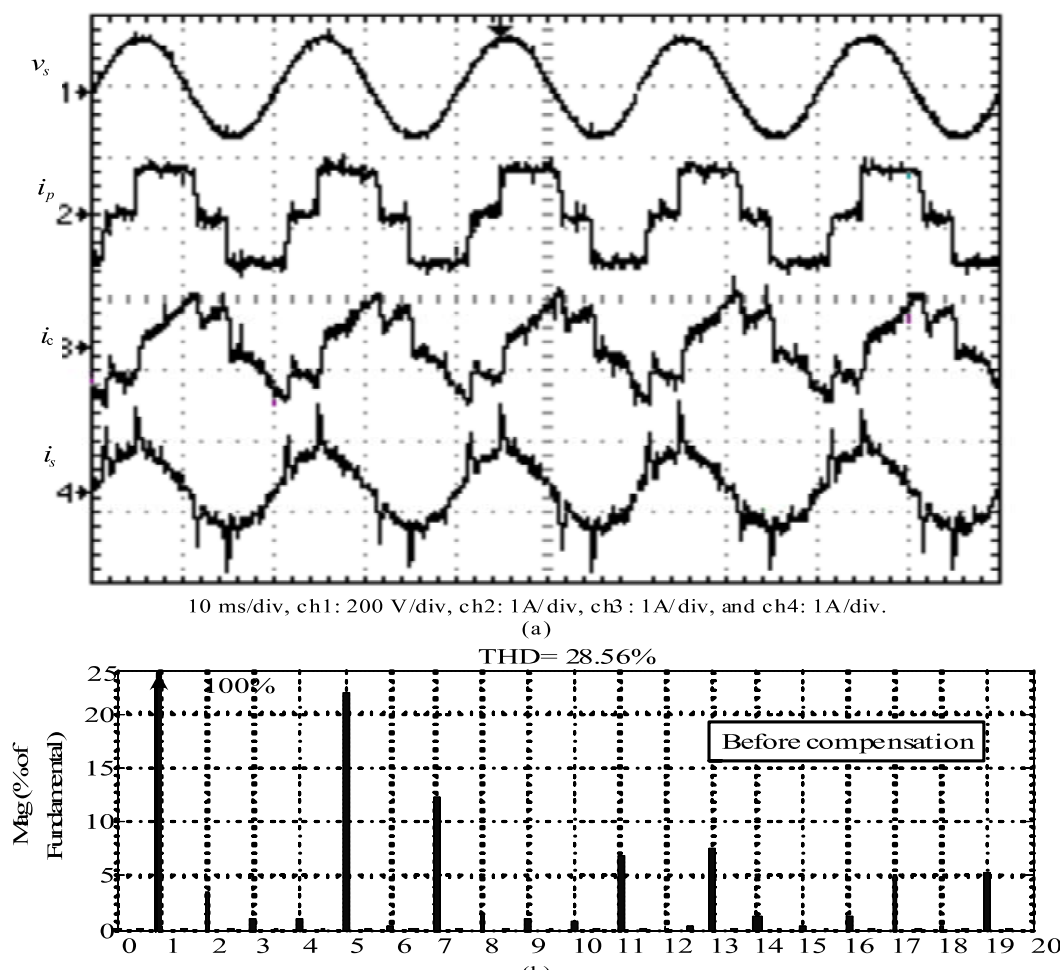

(b)

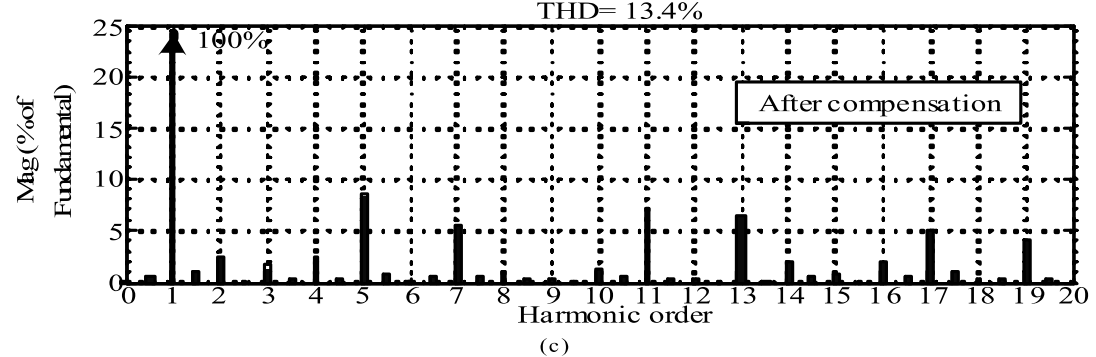

Figure 3. Configuration \#1 practical results at $\alpha=45^{\circ}$ : (a) current waveforms, and (b) \& (c) supply current spectrum before and after compensation, respectively.

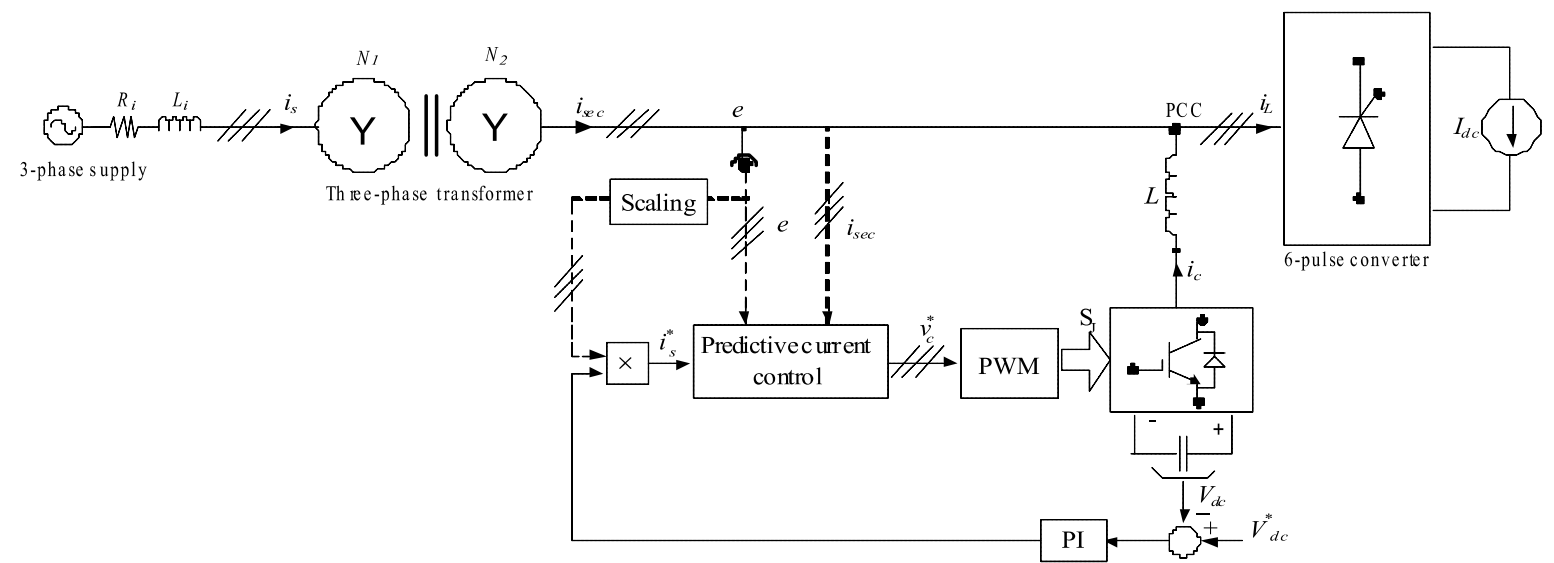

Figure 4. Configuration \#2 APF on the secondary side.

supply phase voltage. The spectra of the compensated $i_{\text {sec }}$ and are shown in Figs. $5 \mathrm{f}$ and $5 \mathrm{~g}$, respectively. From the simulation results, it can be observed that the $M V$ transformer had a negligible effect on the compensated system performance, as the THD of $i_{\text {sec }}$ and $i_{s}$ were virtually the same as what can be seen in configuration \#1. The achieved input power factor $(0.992$ lagging) indicates that reactive power was absorbed by the transformer. However, the $R M S$ filter current increases from 41.2 A, (configuration \#1), to $66.5 \mathrm{~A}$, (configuration \#2). With the same inverter switching frequency, the same performance was achieved for both configurations, but with a lower voltage rated $A P F$. Compensation on the secondary avoided har- 
(a)

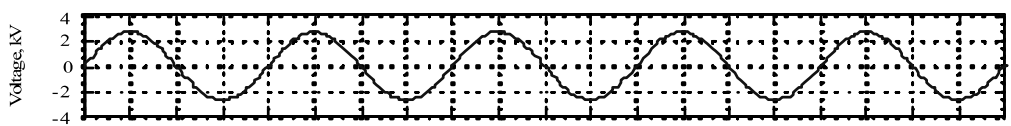

(b)

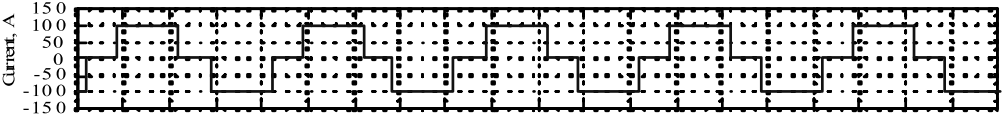

(c)

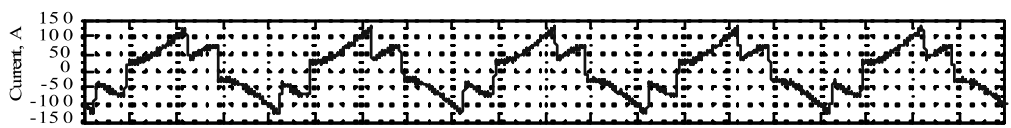

(d)

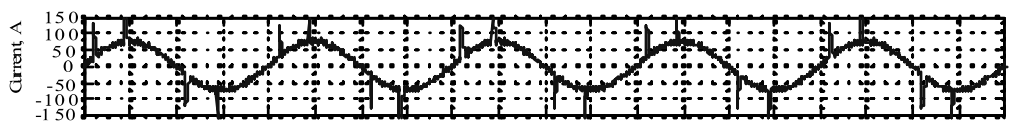

(e)

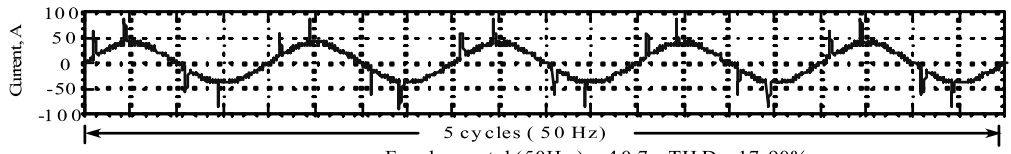

(f)

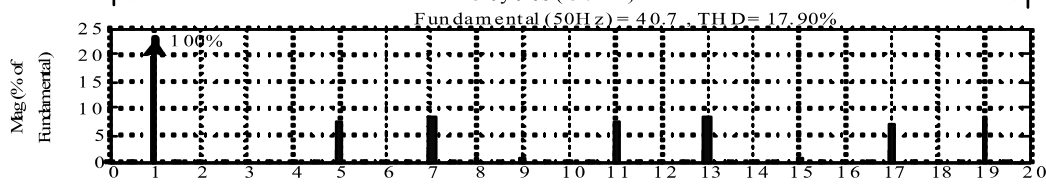

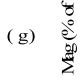

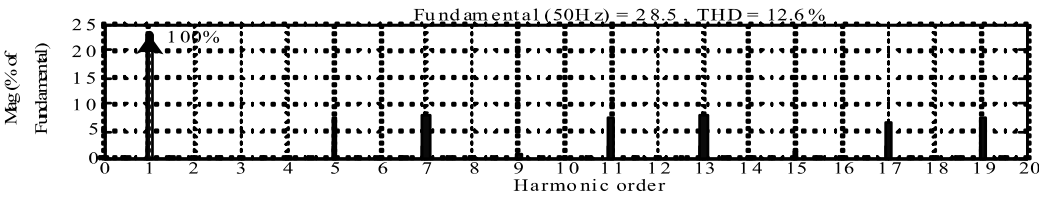

Figure 5. Configuration \#2 for $\alpha=45^{\circ}$; (a) supply phase voltage, $v_{s}$, (b) converter current, $i_{t}$, (c) filter current $i_{s}$, (d) compensated secondary current, $i_{s e c}$, (e) compensated supply current, $i_{s e c}$, (f) spectrum of $i_{s e c}$, (g) spectrum of $i_{s}$.

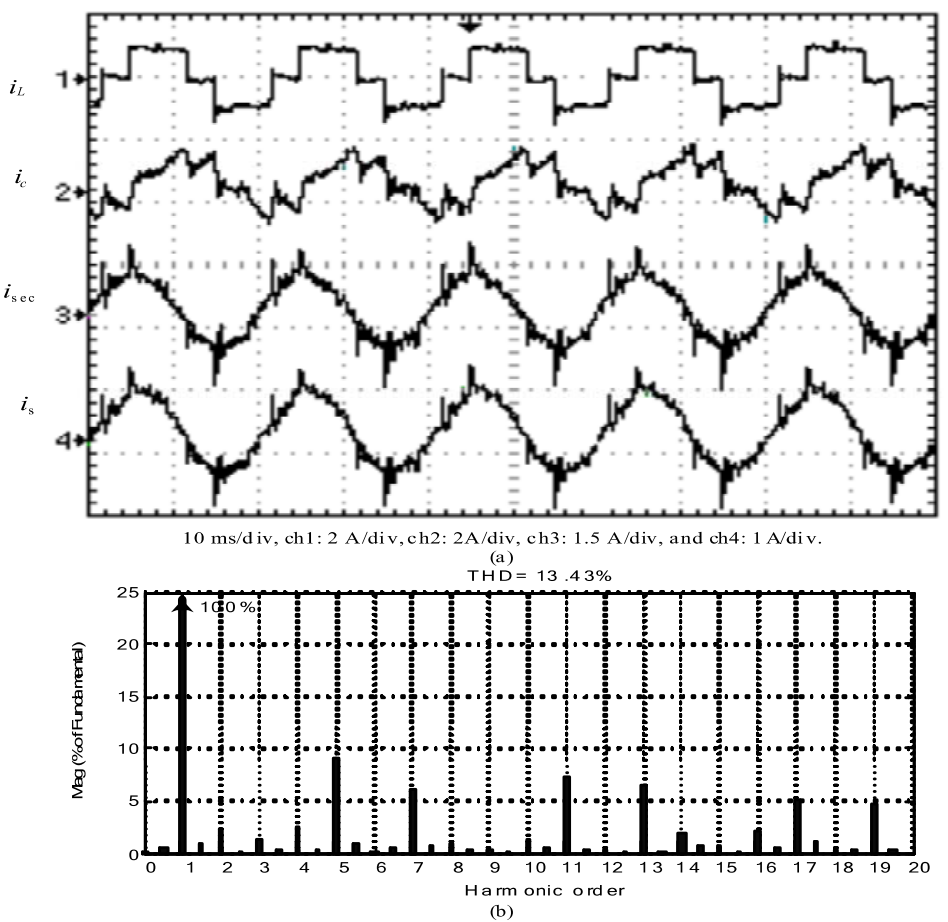

Figure 6. Configuration $\# 2$ practical results at $\alpha=45^{\circ}$ : (a) current waveforms and (b) spectrum of compensated supply current $i_{s}$.

monic and the reactive currents passing through the transformer; consequently, the transformer harmonic burden was reduced.

\subsection{Practical Results}

Three-phase secondary side interfacing inductors of $5 \mathrm{mH}$ were used and the capacitor voltage was con- 


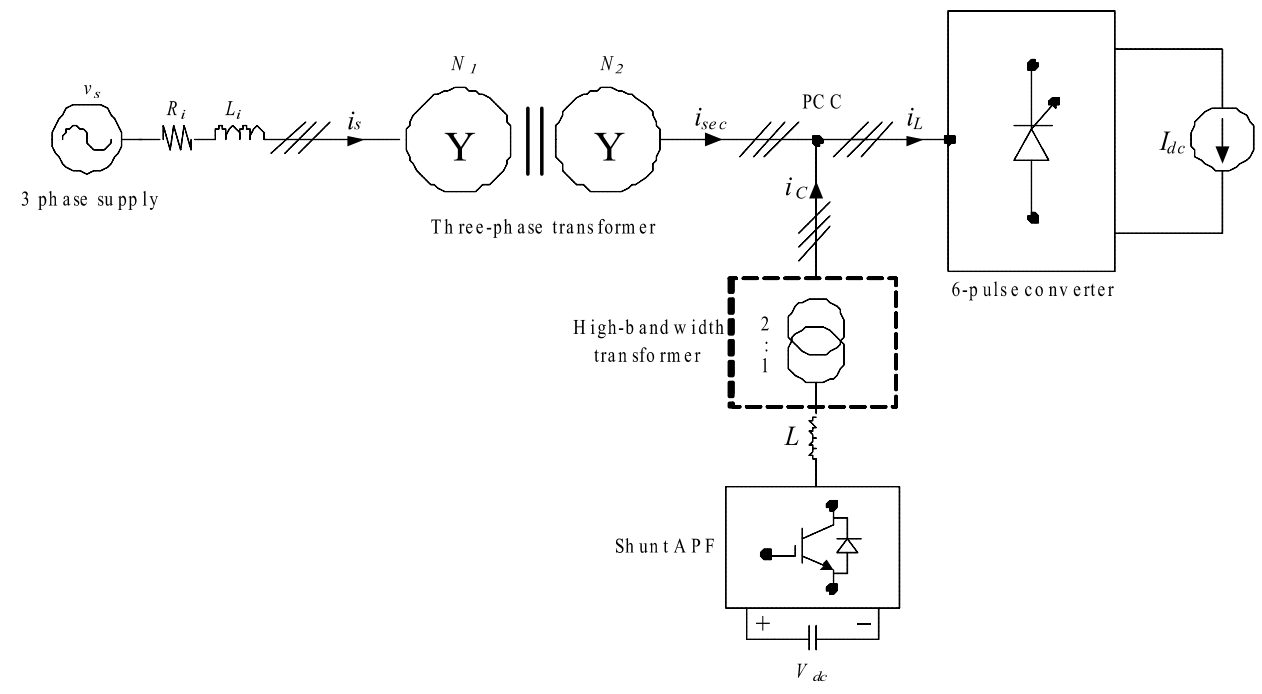

Figure 7. Configuration \#3 APF in the secondary side with a high quality stepdown transformer.

(a)

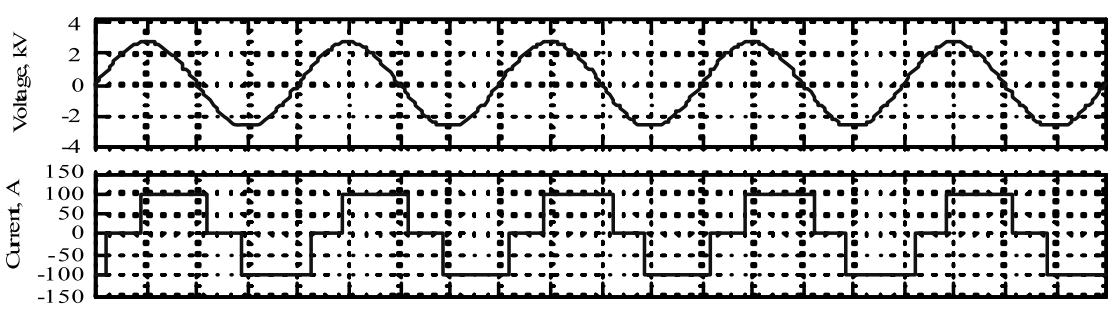

(c)

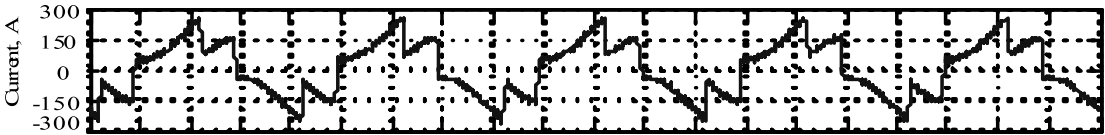

(d)
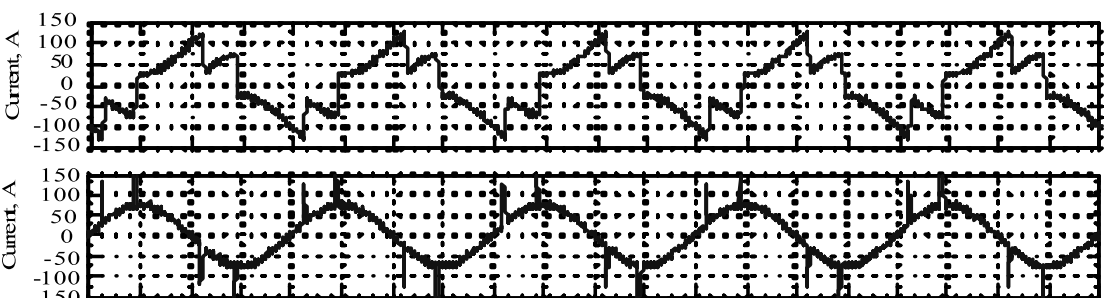

(e)
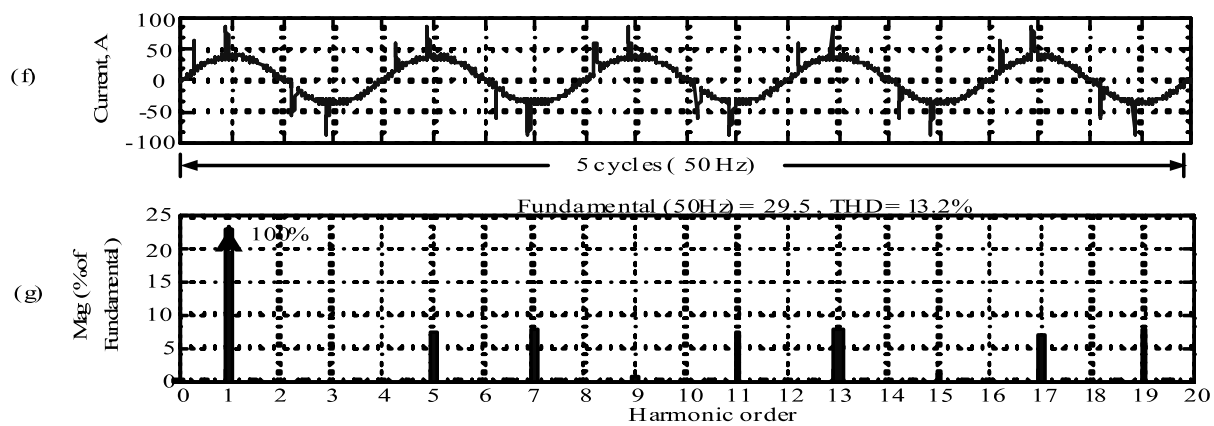

Figure 8. Configuration $\# 3$ at $\alpha=45^{\circ}$; (a) supply phase voltage, $v_{s}$, (b) converter current, $i_{t}$, (c) filter current, $i_{f}$, (d) compensation current, $i_{c}$, (e) compensated secondary current, $i_{\text {sec }}$, (f) compensated supply current, $i_{s}$, (g) spectrum of compensated supply current.

trolled at 220V. The experimental results for $\alpha=45$ are shown in part Fig. 6a. The $i_{f}$ compensated for the $i_{L}$, resulting in the isec and, consequently, the $i_{s}$ was compensated for. The spectrum of the practical recorded supply current after activating the $A P F$ is shown in Fig. 6b. The THD was improved from $28 \%$ to $13.43 \%$ and the power factor was improved from 0.6 to 0.92 lagging. 
Table 1. Configuraton performance before compensation.

\begin{tabular}{ccccccc}
\hline Configuration & $\begin{array}{c}\text { Firing } \\
\text { angle }\end{array}$ & $\begin{array}{c}\text { Fundamental } \\
\text { rms (A) }\end{array}$ & $\begin{array}{c}\text { THD } \\
\%\end{array}$ & $\begin{array}{c}\text { Power } \\
\text { factor } \\
\text { lagging }\end{array}$ & $\begin{array}{c}\text { Input } \\
\text { power } \\
(\mathbf{k W})\end{array}$ & $\begin{array}{c}\boldsymbol{i}_{T} \\
(\mathbf{A})\end{array}$ \\
\hline \multirow{2}{*}{1} & $0^{\circ}$ & 40.1 & 25.5 & 0.955 & 218.89 & - \\
& $45^{\circ}$ & 41.6 & 26.5 & 0.60 & 133.15 & - \\
2 & $0^{\circ}$ & 40.1 & 25.5 & 0.955 & 218.89 & - \\
& $45^{\circ}$ & 40.7 & 25.2 & 0.60 & 139.6 & - \\
3 & $0^{\circ}$ & 39.6 & 28.5 & 0.956 & 216.38 & - \\
\hline
\end{tabular}

Table 2. Configuration performance after compensation.

\begin{tabular}{cccccccc}
\hline $\begin{array}{c}\text { Configu- } \\
\text { ration }\end{array}$ & $\begin{array}{c}\text { Firing } \\
\text { angle } \boldsymbol{\alpha}\end{array}$ & $\begin{array}{c}\text { Fundam } \\
\text { ental } \\
\text { rms (A) }\end{array}$ & $\begin{array}{c}\text { THD } \\
\text { \% }\end{array}$ & $\begin{array}{c}\text { Power } \\
\text { factor } \\
\text { Lagging }\end{array}$ & $\begin{array}{c}\text { Input } \\
\text { power } \\
\text { (kW) }\end{array}$ & $\begin{array}{c}\text { Filter } \\
\text { current } \\
\text { rms (A) }\end{array}$ & $\begin{array}{c}\boldsymbol{i}_{T} \\
\text { (A) }\end{array}$ \\
\hline \multirow{2}{*}{1} & $0^{\circ}$ & 39.4 & 4.6 & 0.99 & 223.4 & 11.7 & - \\
& $45^{\circ}$ & 28.7 & 12.8 & 0.99 & 162.7 & 41.8 & - \\
2 & $0^{\circ}$ & 39.5 & 4.6 & 0.99 & 224 & 23.2 & - \\
& $45^{\circ}$ & 28.5 & 12.6 & 0.99 & 162 & 66.5 & - \\
& $0^{\circ}$ & 39.5 & 4.3 & 0.99 & 227 & 46.5 & - \\
\hline
\end{tabular}

\section{Configuration \# 3}

Filter side voltage reduction can be achieved by using the transformer coupling configuration shown in Fig. 7. As a case study, the turns ratio of the high bandwidth APF transformer was 2:1. This stepped down the PCC voltage to $825 \mathrm{~V}$ and allowed the interfacing inductance to be reduced from $5 \mathrm{mH}$ to $2 \mathrm{mH}$. The switching frequency was $3.6 \mathrm{kHz}$ and the capacitor voltage was controlled at a reduced voltage of 1.8 $\mathrm{kV}$ (3.7 kV in configuration \#2). The simulation results for $\alpha=45$ are shown in Figs. 8a-f. The frontend transformer secondary phase voltage was used to extract the $i_{\text {sec }}{ }^{*}$. The supply phase voltage, the converter current, $i_{L}$, and the $i_{f}$, are shown in parts Figs. $8 \mathrm{a}-\mathrm{c}$, respectively. The $M V$-side of the $A P F$ transformer $i_{c}$ is shown in Fig. 8d. The filter $R M S$ current was $124.5 \mathrm{~A}$. The $i_{\text {sec }}$ is shown in Fig. 8e. The compensated secondar current is shown in Fig. $8 \mathrm{f}$ and was sinusoidal and in phase with the supply phase voltage. The spectrum of the compensated supply current is shown in Fig. 8g. This control system achieves 29A of the $R M S$ fundamental supply current and a $T H D$ of $13.2 \%$ with an input power factor of 0.991 lagging. The capacitor voltage was controlled at half the voltage of configuration \#2 but the filter current was doubled as a result of utilizing the $A P F \quad 2: 1$ high-bandwidth step-down transformer.
The matching transformer core material was required of being capable of transmitting the highest required harmonic compensating component frequency.

\section{Conclusions}

The $A P F$ used in three different configurations compensated both the supply current and input power factor of a 6-pulse converter system. Configuration \#1 is restricted to $M V$ applications as the operating voltage of the $A P F$ inverter semiconductor switches and the switching frequency are limited. Configurations 2 and 3 overcome the voltage problem as the compensation is on the secondary side of the front end transformer. All the configurations achieve virtually the same supply current $T H D$ and the $p f$ is improved to near unity. Configuration 3 offers reduced voltage stresses on the semiconductor devices but the filter current is doubled with respect to configuration $\# 2$. Table 1 shows the configuration performances before compensation while Table 2 shows the configuration performance after compensation. The THD follows the standard at zero firing angle however, if the firing angle is bigger than zero the $T H D$ is increased by nature even the system is compensated. The selection of the $A P F$ position depends on voltage level and user. No clear conclusion can be made about which configuration is the best. If the voltage needs to be reduced than configuration $\# 1$ is not suitable. If there is no 
problem with switches current and voltage is required to be lower, configuration 3 is the preferred choice.

\section{References}

Akagi H, Nabae A, Atoh S (1986), Control strategy of active power filters using multiple voltage-source PWM converters. Transaction on IEEE Industrial Applications 22(3):460.

Akagi H (1996), New trends in active filters for power conditioning. Transactions on IEEE Industry Applications 32(6):1312-1322.

Akagi H (2005), Active Harmonic Filters. Proceedings of the IEEE 93(12):2128-2141.

Anuradha BS, Kothari DP (1998), Analysis of a novel active filter for balancing and reactive power compensation. IEE Conference on Power Electronics and Variable Speed Drives 456:57-62.

Bose BK (2002), Modern power electronics and AC drives. Prentice Hall, Upper Saddle River.

Bose BK (2009), Power electronics and motor drives recent progress and perspective. Transactions on IEEE Industrial Electronics 56(2):581-588.

Cheng PT, Bhattacharya S, Divan DM (1999), Application of dominant harmonic active filter system with 12 pulse nonlinear loads. Transactions on IEEE Power Delivery 14(2):642647.

Choi S, Oh J, Cho J (2000), Multi-pulse converters for high voltage and high power applications. Third International Power Electronics and Motion Control Conference IPEMC 2000 (3):1019-1024.

Corasaniti VF, Barbieri MB, Arnera PL, Valla MI (2008), Comparison of active filters topologies in medium voltage distribution power systems. Power and Energy Society General Meeting Conversion and Delivery of Electrical Energy in the 21st Century: 1-8.

El-Habrouk M, Darwish MK, Mehta P (2000), Active power filters: A review. IEEE Proceeding on Electric Power Application 147(5):403-413.

Freitas LCG, Simoes MG, Canesin CA, Freitas LC (2007), Performance evaluation of a novel hybrid multipulse rectifier for utility interface of power electronic converters. Transactions on IEEE Industrial Electronics 54(6):3030-3041.

Hamad MS, Masoud MI, Finney SJ, Williams BW (2012), Medium voltage 12-pulse converter: AC side compensation using a shunt active power filter in a novel front end transformer configuration. Transaction on IET Power Electron 5:1315-1323.
Huang SJ, Wu JC (1999), A control algorithm for three-phase three-wired active power filters under non-ideal mains voltages. Transaction on IEEE Power Electronics 14:153-760.

Massouda AM, Finney SJ, Williams BW (2004), Predictive current control of a shunt active power filter. 35th IEEE Power Electronics Specialists Conference, Aachen. Germany PESC'04:78038399.

Massoud ${ }^{b}$ AM, Finney SJ, Williams BW (2004), Review of harmonic current extraction techniques for an active power filter. 11th International Conference on Harmonics and Quality of Power:154-159.

Rahmani S, Mendalek N, Al-haddad K (2010), Experimental design of nonlinear control technique for three-phase shunt active power filter. Transactions on IEEE Industrial Electronics 57(10):3364-3375.

Rashid MH (2001), Power Electronics: Handbook. Academic Press, Canada.

Rice DE (1994), A detailed analysis of six-pulse converter harmonic currents. Transactions on IEEE Industry Applications 30(2):294-304.

Routimo M, Salo M, Tuusa H (2007), Comparison of voltage-source and current-source shunt active power filters. Transactions on IEEE Power Electronics 22(2):636-643.

Singh B, Solanki J (2009), An implementation of an adaptive control algorithm for a three-phase shunt active filter. Transactions on IEEE Industrial Electronics 56(8):2811-2820.

Takeda M, Ikeda K, Teramoto A, Htsuka T (1988), Harmonic current and reactive power compensation with an active filter. IEEE Power Electronics Specialists Conference, PESC 88:1174-1179.

Tenca P, Lipo TA (2004), Reduced cost current-source topology improving the harmonic spectrum through on-line functional minimization. $35^{\text {th }}$ IEEE Power Electronics Specialists Conference, PESC'04 (4):2829-2835.

Wiechmann EP, Aqueveque P, Burgos R, Rodriguez J (2008), On the efficiency of voltage source and current source inverters for high-power drives. Transactions on IEEE Industrial Electronics 55(4):1771-1782.

Williams BW [Online]. Power Electronics: Devices, Drivers, Applications, and Passive Components. Available eee.strath.ac.uk/ bwwilliams/book.htm.

Wu B (2006), High-Power Converters and AC Drives. Wiley-IEEE Press. 


\section{Appendix}

Appendix I: $M V$ transformer parameters.

\begin{tabular}{cc}
\hline Parameter & Value \\
\hline Rated kVA & $250 \mathrm{kVA}$ \\
Primary/secondary Voltage & $3.3 / 1650 \mathrm{kV}$ \\
$R_{I}$ or $R^{\prime}{ }_{2}(\mathrm{pu})$ & 0.005 \\
$X_{I}$ or $X_{2}^{\prime}(\mathrm{pu})$ & 0.01 \\
$X_{m}(\mathrm{pu})$ & 75 \\
$R_{m}(\mathrm{pu})$ & 100 \\
\hline
\end{tabular}

Appendix II: Prototype transformer parameters.

\begin{tabular}{cc}
\hline Parameter & Value \\
\hline Rated kVA & $2 \mathrm{kVA}$ \\
Primary/secondary Voltage & $420 / 210 \mathrm{~V}$ \\
$R_{1}(\mathrm{pu})$ & 0.02 \\
$X_{1}(\mathrm{pu})$ & 0.02 \\
$R^{\prime}{ }_{2}(\mathrm{pu})$, for $\mathrm{a}_{\mathrm{t}}=50 \%$ & 0.009 \\
$X^{\prime}{ }_{2}(\mathrm{pu})$, for $\mathrm{a}_{\mathrm{t}}=50 \%$ & 0.023 \\
$X_{m}(\mathrm{pu})$ & 22 \\
$R_{m}(\mathrm{pu})$ & 102 \\
\hline
\end{tabular}

Appendix III: $M V$ system operating parameters.

\begin{tabular}{cccc}
\hline $\begin{array}{c}\text { System } \\
\text { para meters }\end{array}$ & Configuration \#1 & Configuration \#2 & Configuration \#3 \\
\hline $\begin{array}{c}P C C \\
\text { voltage, } v_{a b}\end{array}$ & $3.5 \mathrm{kV}$ & $1.65 \mathrm{kV}$ & $825 \mathrm{~V}$ \\
$\begin{array}{c}\text { Load } \\
\text { current, } I_{d c}\end{array}$ & $100 \mathrm{~A}$ & $100 \mathrm{~A}$ & $100 \mathrm{~A}$ \\
$\begin{array}{c}\text { Interfacing } \\
\text { inductance, } \\
L\end{array}$ & $12 \mathrm{mH}$ & $5 \mathrm{mH}$ & $2 \mathrm{mH}$ \\
$\begin{array}{c}\text { DC side } \\
\text { capacitance, } \\
C\end{array}$ & $5 \mu \mathrm{F}$ & $5 \mu \mathrm{F}$ & $5 \mu \mathrm{F}$ \\
$\begin{array}{c}\text { Switching } \\
\text { frequency, } \\
f_{s w}\end{array}$ & $3.6 \mathrm{kHz}$ & $3.6 \mathrm{kHz}$ & $3.6 \mathrm{kHz}$ \\
$\begin{array}{c}\text { Capacitor } \\
\text { voltage }\end{array}$ & $7.6 \mathrm{kV}$ & $3.7 \mathrm{kV}$ & $1.8 \mathrm{kV}$ \\
\hline
\end{tabular}

